\title{
Review of: "The first true millipede-1306 legs long"
}

\author{
H. K. S. de Zoysa ${ }^{1}$ \\ 1 Rajarata University of Sri Lanka
}

Potential competing interests: The author(s) declared that no potential competing interests exist.

This study is very impressive and findings are valuable as the deep troglofauna are difficult to explore due to their presence deep below the soil. here authors have described and compared the newly found millipede species with the previous animals by comparison of their phylogeny. This is very important for these types of classification for future studies to get clear about the affinity of each species. However, in my opinion, these findings make a new chapter for future studies on millipedes as the scientists and researchers should have to consider new sampling techniques as still many species can be found under soil more than $50 \mathrm{~m}$ below. Hence, I think this is a very important and invaluable finding together with the new thinking way to explore the millipedes species in future studies. 